\title{
Post-Natal Cytokine Levels of Neonates of Seropositive Mothers: An Indication of Vertical Transmission?
}

\author{
Adeoti $\mathrm{OM}^{1,2 *}$ Adesina $\mathrm{DA}^{3}$ \\ ${ }^{1}$ The Oke-Ogun Polytechnic, Saki, Nigeria \\ ${ }^{2}$ Cellular Parasitology Programme, Department of Zoology, University Ibadan, Nigeria \\ ${ }^{3}$ Department of Microbiology, University of Ibadan, Nigeria
}

\begin{abstract}
Studies have implicated increased plasma levels of TNF- $\alpha$ in clinical malaria and vertical transmission of HIV. The intricate imbalances in cytokines levels threaten successful pregnancies. In this study, pregnant women were polled-stratified for interview and subsequently enrolled in a longitudinal study for eighteen months in the endemic area of Saki. Spot Blood samples $(2 \mathrm{~mL})$ were collected for laboratory diagnosis of HIV and Malaria at delivery and post natal. The plasma concentration of cytokines: TNF- $\alpha$, IL-2, IL-10 and IFN- $\gamma$ was determined by cytokine ELISA techniques. Forty-five (30.2\%) of pregnant women were sero-positive with $63.3 \%$ in babies. The co-infection rate was $22.8 \%$ in pregnant women and $26.3 \%$ in babies. The levels of TNF- $\alpha$ was high $\left(30.0 \times 10^{-3} \mathrm{pg} / \mu \mathrm{L}\right)$ in non-infected babies at delivery whereas IL-2, IL-10 and IFN- $\gamma$ peaked at $\left(7010^{-3} \mathrm{pg} / \mu \mathrm{L}, 40 \times 10^{-3} \mathrm{pg} / \mu \mathrm{L}\right)$ and $16.0 \times 10^{-3} \mathrm{pg} / \mu \mathrm{L}$ respectively in uninfected babies. At delivery, the levels of TNF- $\alpha$, IL-2, IL-10 and IFN- $\gamma$ was $18.3 \times 10^{-3} \mathrm{pg} / \mu \mathrm{L}, 69.8 \times 10^{-3} \mathrm{pg} / \mu \mathrm{L}, 41.0 \times 10^{-3} \mathrm{pg} / \mu \mathrm{L}$ and rise to $28.3 \times 10^{-3} \mathrm{pg} / \mu \mathrm{L}$ in co-infected babies. The level of IL-10 was highest in co-infected babies at the second month post-delivery. Also, there was a progressive increase in the level of IFN- $\gamma$ at the third month among the un-infected, coinfected and seropositive babies. The parasite density in co-infected babies in the first three months and the plasma levels of IFN- $\gamma$ and TNF- $\alpha$ could be an indication of vertical transmission of both HIV and P. falciparum.
\end{abstract}

\section{Introduction}

HIV infection poses a great threat to a successful pregnancy outcome, in that a precarious shift from type 1 to type 2 cytokines is necessary for a successful pregnancy; this is, however, reversed in HIV infection and indicates HIV progression $[15,28]$. Malaria induced the production of various cytokines, including interleukins and tumor necrosis factor, which have been shown to stimulate HIV-1 replication [18]. HIV infection appears to impair a pregnant woman's ability to control malaria parasitemia, resulting in more frequent and higher density parasitemia than in HIV-un-infected pregnant women [25]. The TNF- $\alpha$ and IFN- $\gamma$ appear to be protective against the parasite, very high serum concentrations of pro-inflammatory cytokines are associated with great morbidity $[25,13,26,8]$. The current study examined the implication of plasma concentration of two proinflammatory cytokines (TNF- $\alpha$ and IFN- $\gamma$ ) on mother-to-childtransmission of HIV and malaria infection.

\section{Materials and Methods}

The mean temperature of Saki is $33^{\circ} \mathrm{C}$ while the sunshine hours per day range from 3.4 hours in August to 11 hours in February. Rice and roots crops are the main agricultural products. Saki is a Periurban border town of Nigeria and Cotonou. The target population was pregnant women who reported for routine ante-natal check-up. Pregnant mothers who consented to participate in the study after being adequately informed of the project objectives, protocol and benefits were then enrolled. All subjects were encouraged to deliver their babies at the selected hospitals of the project. Thin and thick blood smears were made from each of these samples for microscopy having been stained in 30\% Giemsa (thick) and Leishman (thick). Standardized Parasitemia was performed by counting parasite asexual stages per 200 leukocytes on both thick and thin blood films. The number of parasites per microliter of blood was calculated by assuming an average white blood cell count of $8,000 / \mu \mathrm{L}$. The preparation of both thick and thin blood films for confirmation of parasitemia followed the methods described by [8]. The degree of parasitemia was graded by modified technique of [31] into Mild Low (1-999/ $\mu \mathrm{L})$ and High above (>1000$9999 / \mu \mathrm{L}$ ). They were systematically examined under immersion lens. A negative result was recorded after thorough examination of 100 fields without any parasite. Quality control was ensured, by using freshly reconstituted filter Giemsa stains for parasitemia.

\section{Measurement of cytokines in the plasma by ELISA}

The concentration of IL-10 Anti-inflammatory (IL-10) and Proinflammatory cytokines (IL-2, IFN- $\gamma$, TNF- $\alpha$ ) of 179 samples were measured by using ELISA techniques. The cytokine detection kits purchased from (Mabtech, Stockholm, Sweden) were used for this assay. ELISA plates (Corning Incorporated, Nunc Maxicorb) were coated with the purified anti-cytokine capture monoclonal antibody to $(1 \mu \mathrm{g} / \mathrm{ml})$ in a coating buffer (Sodium bicarbonate). Monoclonal antibodies used were TNF- $\alpha$, I-D1K, 9D7 and IL-2-I for TNF- $\alpha$, IFN- $\gamma$, IL-10 and IL-2 respectively. One hundred microliter $(100 \mu \mathrm{L})$ of diluted antibody was added to each well, sealed in order to prevent

Correspondence to: Adeoti OM, The Oke-Ogun Polytechnic, Saki, Nigeria, Tel: +234-806-7285-175; E-mail: txy23m@yahoo.com

Key words: ELISA, polled-interviewed, vertical transmission, P. falciparum, seropositive, post-natal

Received: September 02, 2017; Accepted: September 25, 2017; Published: September 28, 2017 
evaporation and incubated at $4^{\circ} \mathrm{C}$ overnight. The plates were washed with phosphate buffered saline-Tween 20 (PBS/Tween) and blocked with $200 \mu \mathrm{L}$ of blocking ( $0.05 \%$ skimmed milk) appropriately diluted in $\mathrm{PBS} /$ Tween and incubated at room temperature 2 hours and for dilution of standards and plasma samples. Specific binding and blocking buffer ( $1 \%$ milk) were applied to the plates immediately before the addition of the samples and standards and incubated at $4^{\circ} \mathrm{C}$ overnight. The plates were washed 4 times in duplicates (1:1) with PBS/Tween into the precoated plates. Bound cytokines were assayed using Biotinylated anticytokine detection monoclonal antibody which was diluted to $2 \mu \mathrm{g} / \mathrm{mL}$ in blocking buffer (PBS/Tween) followed by $100 \mu \mathrm{L}$ of diluted antibody was added to each well and incubated at room temperature for 2 hours. The enzyme conjugate (Streptavidin-ALP) was diluted to its pre-titrated optimal concentration in blocking buffer/Tween by using a 1:1000 dilution factor according to the manufacturer's instruction. $100 \mu \mathrm{L}$ of diluted enzyme conjugate was added per well and incubated at room temperature for 45 minutes. The substrate (Para Nitro Phenyl Phosphate) was prepared by dissolving $20 \mu \mathrm{g}$ in $20 \mathrm{ml}$ of de-ionized water thereafter $150 \mu \mathrm{L}$ was dispensed into each well. The plates were incubated at room temperature in the dark for colour development for 80 minutes. The optical density for each well was determined with a Biotrak II microplate reader at $405 \mathrm{~nm}$. The optimal absorbance values were obtained by plotting a standard curve. The average ODs (Optical Density) were calculated and its corresponding concentrations were plotted on graph as the standard graph.

\section{Statistical Analysis}

Subjects' infection status were adopted from similar literatures $[1,32]$ by using students t-test and ANOVA by using SPSS version 15 at $\mathrm{p}=0.05$ as the level of significance.

\section{Results}

Low level of TNF- $\alpha$ was observed from $30.0 \times 10^{-3} \mathrm{pg} / \mu \mathrm{L}$ in uninfected to $17.0 \times 10^{-3} \mathrm{pg} / \mu \mathrm{L}, 20.0 \times 10^{-3} \mathrm{pg} / \mu \mathrm{L}$ and $0.8 \times 10^{-3} \mathrm{pg} / \mu \mathrm{L}$ in co-infected HIV only and those infected with $P$. falciparum a six month only. The mean plasma concentrations of cytokines in babies during the follow-up (Figure 1) and post-delivery is shown in Figure 2 -4. TNF- $\alpha$ level were significantly higher from $15.0 \times 10^{-3} \mathrm{pg} / \mu \mathrm{L}$ in un-infected to $26.0 \times 10^{-3} \mathrm{pg} / \mu \mathrm{L}$ in co-infected and $30.0 \times 10^{-3} \mathrm{pg} / \mu \mathrm{L}$ in HIV infected. However, the plasma concentration of TNF- $\alpha$ decreased progressively $\left(30.0 \times 10^{-3} \mathrm{pg} / \mu \mathrm{L}\right)$ in un-infected to $\left(10.0 \times 10^{-3} \mathrm{pg} / \mu \mathrm{L}\right)$ in malaria infected babies. The levels of TNF- $a$ reduced in uninfected and HIV infected babies in second and third month post-delivery.

From figure 1, the levels of TNF- $\alpha$ is high $\left(30.0 \times 10^{-3} \mathrm{pg} / \mu \mathrm{L}\right)$ in non-infected babies at delivery whereas IL-2, IL-10 and IFN- $\gamma$ peaked at $\left(70 \times 10^{-3} \mathrm{pg} / \mu \mathrm{L}, 40 \times 10^{-3} \mathrm{pg} / \mu \mathrm{L}\right)$ and $16.0 \times 10^{-3} \mathrm{pg} / \mu \mathrm{L}$ respectively in uninfected babies. At delivery, the levels of TNF- $\alpha$, IL-2, IL-10 and IFN- $\gamma$ was $18.3 \times 10^{-3} \mathrm{pg} / \mu \mathrm{L}, 69.8 \times 10^{-3} \mathrm{pg} / \mu \mathrm{L}, 41.0 \times 10^{-3} \mathrm{pg} / \mu \mathrm{L}$ and rise to $28.3 \times 10^{-3} \mathrm{pg} / \mu \mathrm{L}$ in co-infected babies. Figure 5 showed that TNF- $\alpha$ decreased progressively in uninfected and HIV infected post-delivery babies. IL-2 levels increased in the second month in no-infection categories of babies. In co-infected babies, there was a progressive decrease in the cytokine levels as indicated in figure 2. The level of IL-10 was highest in co-infected babies at the second month post-delivery (Figure 3 ). Figure 2 showed progressive increase in the level of IFN- $\gamma$ at the third month among the un-infected, co-infected and seropositive babies.

\section{Discussion}

However, the parasite density in co-infected babies (in the first three months post-delivery) could be suggested as vertical transmission

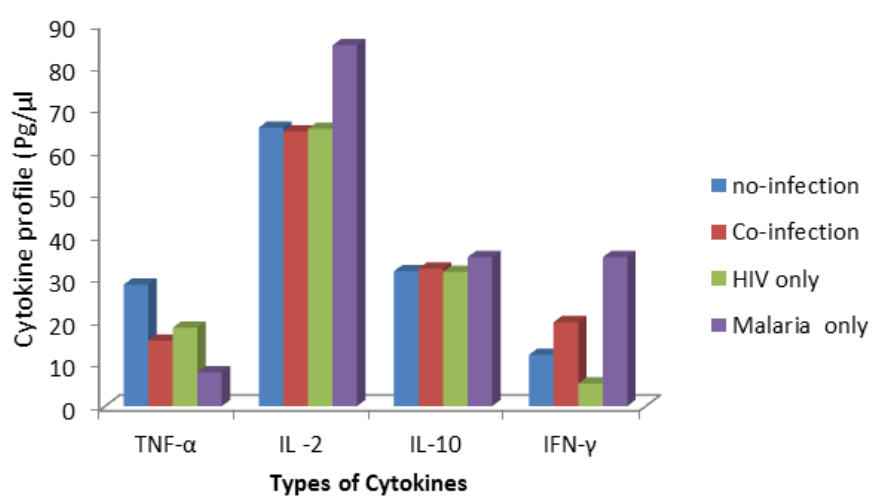

Figure 1. Mean plasma cytokine levels at delivery and categories of infection in babies born to the HIV infected mothers.

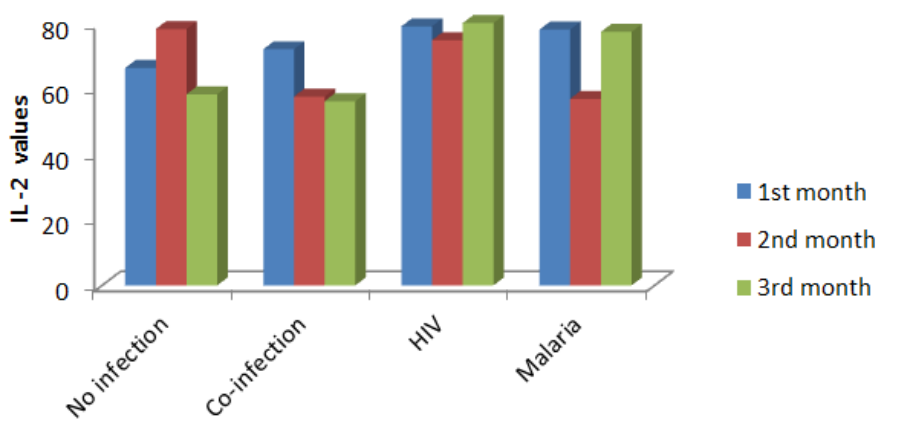

Categories of Infections

Figure 2. IL-2 levels and classes of infection in babies three month post-delivery.

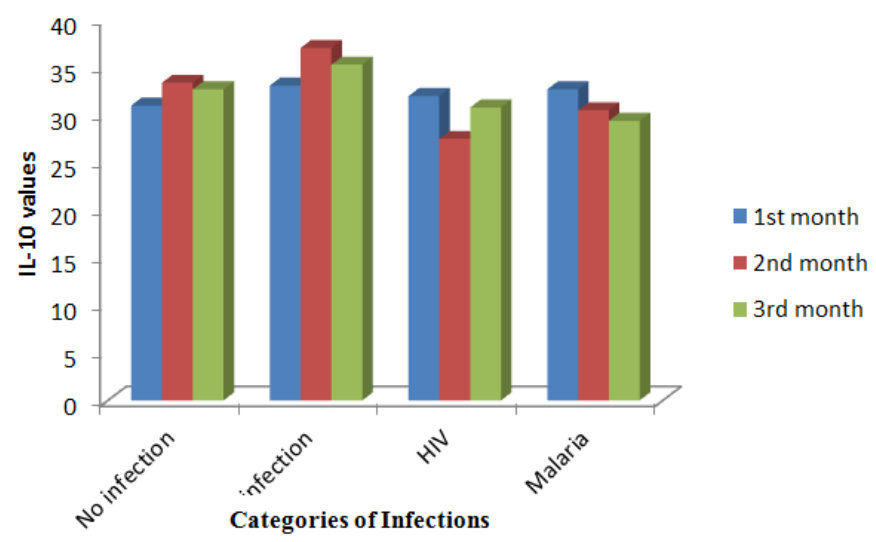

Figure 3. IL-10 levels and classes of infection in babies three month post-delivery.

of both HIV and P. falciparum supporting the fact that both infections remain major public health issues in Nigeria $[7,12,14]$. The decrease in the parasite density from the fourth months could be as a result of transient potency of the innate immunity to clear parasitemia within the first six months of life. There was no mortality recorded in this study was a plus for the effectiveness of antimalarial and HAART was unlike the outcome of a prospective study in Malawi, where the maternal mortality rate within six weeks of pregnancy was 370 per 100,000 women [27]. Perhaps, reasons for this differences in these studies may lie in the fact that both antimalarial and HAART are effective in reducing mother-to-child-transmission of HIV [21,33,35]. Low circulating levels of IFN- $\gamma$ have been previously associated with severe malaria and mortality in children especially infants with cerebral 


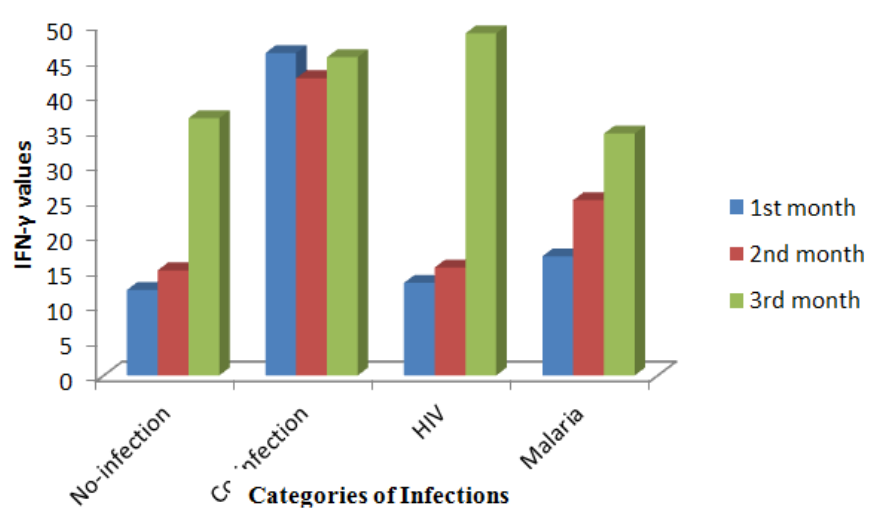

Figure 4. IFN- $\gamma$ levels and classes of infection in babies three month post-delivery.

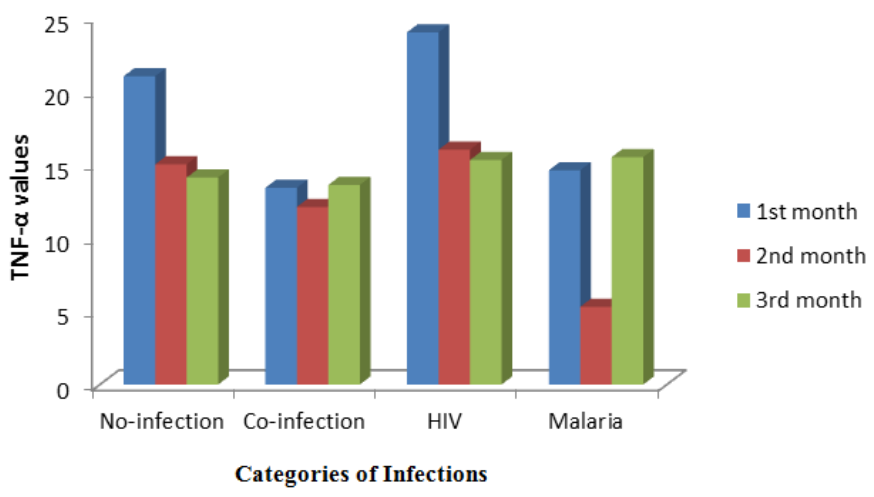

Figure 5. TNF- $\alpha$ level in the infected groups' status during Post-delivery follow-up in babies.

malaria. The concentration of IFN- $\gamma$ followed the same trend that was observed in the levels of IL- 2 in this study. IFN- $\gamma$ was expected to have played a crucial role in the clearance of intracellular parasites [24], and associated with high malaria severity in young African children $[10,30]$. Its reduction in all infectious cases (especially in co-infected and HIV infected only) in this study could be regarded as being pathological biomarker for impaired resistance against infection which corroborated the result obtained in similar study by Angulo et al. [2] and Ned et al. [29].

It was established that in newborns of HIV infected mothers, HIV and falciparum co-infection was a strong predictor of adverse perinatal outcomes (anemia), and indicative of impaired immunity thereby increasing the susceptibility of newborn to infections [22]. The general reduction in TNF- $\alpha$ level that was observed in this study was a confirmation of that assertion. As suggested earlier, the similar low levels of observed in newborns of HIV infected could be an indication of vertical transmission of impaired immunity from their HIV infected mothers. This might have led to increased IFN- $\gamma$ concentration among co-infected babies and malaria only infected. The high level of IFN- $\gamma$ in non-infected mothers compared to the levels of IL-10 was supposed to be deleterious to successful pregnancy and a comparative indication of severe perinatal outcome and high parasite density which would be potentially harmful for the pregnancy $[10,11,30]$.

The pattern observed in the level of IFN- $\gamma$ in this study contradicts studies $[16,29,34,36]$; the concentration of IFN- $\gamma$ was low upon infection. Low circulating levels of IFN- $\gamma$ have been previously associated with severe malaria and mortality in children especially infants with cerebral malaria. The concentration of IFN $-\gamma$ followed the same trend that was observed in the levels of IL-2 in this study. IFN- $\gamma$ was expected to have played a crucial role in the clearance of intracellular parasites [24], and associated with high in malaria severity in young African children $[10,30]$. The general reduction in TNF- $\alpha$ level that was observed in this study was a confirmation of that assertion. This might have led to increased IFN- $\gamma$ concentration among co-infected babies and malaria only infected. The high level of IFN- $\gamma$ in non-infected mothers compared to the levels of IL-10 was supposed to be deleterious to successful pregnancy and a comparative indication of severe perinatal outcome and high parasite density which would be potentially harmful for the pregnancy $[10,11,30]$. The pro-inflammatory cytokine levels in this study tended to be low with either $P$. falciparum or HIV prevalence. This is in contrast with [2] who implicated pro-inflammatory cytokines of Th1 subsets: TNF- $\alpha$ and IFN- $\gamma$ in clinical malaria. However, Ogbodo et al. [31] and Singh et al. [31] noted that pro-inflammatory cytokines in the placental environment served as a stimulant for HIV-1 expression and possible facilitator of mother-to-child-transmission of HIV. It is known that, cytokines which favour the increased incidence of $P$. falciparum infection tend to increase the proliferation or replication of HIV [34].One potential mechanism for this was evaluated in vitro: binding of recombinant $P$. falciparum adhesion to chondroitin sulfate A on human placental cells increased HIV replication in those cells, possibly via TNF-a stimulation [35]. Thus in consonance with Kfutwah et al. [18], Singh and John [34] and Verhoeff et al. [36], TNF- $\alpha$ was suggested as an inducer of viral replication and high levels of IFN- $\gamma$ indicate increase in the chances of mother-to-child-transmission of HIV $[34,35]$. This may serve as an explanation for the observed TNF- $\alpha$ level in this study. The observed increase in TNF- $\alpha$ level among those infected with HIV only and the co-infected women when compared to their uninfected peers, is contrary to recent reports [35,36]. Ordinarily, increased concentrations of TNF- $\alpha$ as reported by Kfutwah et al. [18] was an indication of increased HIV expression and could facilitate MTCT of HIV. However, it is important to note that there was statistical direct relationship between TNF- $\alpha$ and HIV replication but an inverse relationship between IFN- $\gamma$ and HIV infection. Also, in contrast with the study by Kfutwah et al. [18], there was a direct relationship between infection categories and plasma concentration of TNF- $\alpha$.

\section{References}

1. Abaniyie FA McCraken C Kirrvan P Mollo SF Asaolu SO et al. (2013) Ascaris coinfection does not alter malaria-induced anaemia in a cohort of Nigeria Pre School Children. BMC Malaria Journal 12: 1-8.

2. Angulo I, Fresno M (2002) Cytokines in the pathogenesis of and protection against malaria. Clinical and Diagnostic Laboratory Immunology 96: 1145-1152

3. Ariyoshi M., Van der Loeff N, Berry S, Jaffar H (1999) Plasma HIV viral load in relation to burden and Development of AIDS at the Federal Medical Centre Makurdi Nigeria. Nig J Parasitol 26: 7-11.

4. Ayisi JG, van Eijk AM, ter Kuile FO, Kolczak MS, Otieno JA, et al. (2003) The effect of dual infection with HIV and malaria on pregnancy outcome in western Kenya. AIDS 17: 585-594. [Crossref]

5. Ayisi JG, van Eijk AM, ter Kuile FO, Kolczak MS, Otieno JA, et al. (2003) The effect of dual infection with HIV and malaria on pregnancy outcome in western Kenya. AIDS 17: 585-594. [Crossref]

6. Ayouba A, Badaut C, Kfutwah A (2008) Specific stimulation of HIV-1 replication in human placental trophoblasts by an antigen of Plasmodium falciparum AIDS 6: 785-787.

7. Brahambatt H, Sulivan D, Kigozi G, Askin F, Wabwire-Mangen F, et al. (2008) Association of HIV and malaria with Mother-to-Child-Transmission birth outcomes and Child mortality. AIDS 47:472-476

8. Chaouat G, Cayol V, Mairovitz V, Dubanchet S (1999) Localization of the Th2 cytokines IL-3 IL-10 at the murine feto-maternal interface during pregnancy In: Gupta SK editor. Reproductive Immunology 12: 61-70. 
9. Cheesbrough M (2005) District Laboratory practice in Tropical countries. 2nd edition Cambridge: Cambridge University Press 244-51

10. Clark IA, Chaudhri G (1998) Tumour necrosis factor may contribute to the anaemia of malaria by causing dyserythropoiesis and erythro-phagocytosis. Br J Hematol 70: 99-103.

11. lerici M, Seresella M, Colombo F, Fossati S, Sala N, (2000) T- Lymphocyte maturation abnormalities in uninfected newborns and children with vertical exposure to HIV BLOOD 96.12: 3866-3871

12. Dibua UME, Badger-Emeka L, Ugonabo JA (2013) HIV and malaria co-infection: their combined effects on pregnancy outcomes in Anambra State south-East Nigeria. Int $J$ Med Sci 5.10: 438-449

13. El-Far M, El-Sayed IH, El-Motwally AE, Hashem IA, Bakry N (2009) Serum levels of TNF-alpha and antioxidant enzymes and placental TNF alpha expression in unexplained recurrent spontaneous miscarriage. J Physiol Biochem 65: 175-181.

14. Federal Ministry of Health (2011) Global AIDS response country report by Nationa Agency for the Control of AIDS cited at www.unaids.org/endataanalysis/know

15. Feng G, Simpson JA, Chaluluka E, Molyneux ME, Rogerson SJ (2010) Decreasing burden of malaria in pregnancy in Malawi women and its relationship to use of Intermittent Preventive Therapy or bed nets. PLOS ONE 5: 1-9.

16. Fried M, Richard O, Muga Ambrose O, Misore Patrick ED (2012) Malaria Elicits Type 1 Cytokines in the Human Placenta: IFN-? and TNF-a Associated with Pregnancy Outcomes. J Immunol.

17. Hochman S, Kim K (2012) The impact of HIV co-infection on cerebral malaria pathogenesis. Am J Trop Dis Hyg 71: 41-54.

18. Kfutwah A, Marry JY, Lemen B, Leke R, Rousset D, et al. (2009) Plasmodium falciparum infection significantly impairs placental cytokine in HIV-Infected Cameroonian women. PLOS ONE 4: 8114-8118

19. Kfutwah A, Mary JY, Lemen B, Leke R, Rousset D, et al. (2008) Plasmodium falciparum and placental cytokine profiles among pregnant women in relation to their HIV- 1 status possible implications for mother-to-child transmission MTCT) of HIV in Cameroon. Retrovirology Oral Presentation

20. Kfutwah AKW, Marry JY, Nicola MA, Bliase-Boisseau S, Barre-Sinoussi F, et al. (2006) Tumor Necrosis Factor-a stimulate HIV-1 replication in single-cycle infection of Human term placental villi fragments in a time viral dose and envelope dependent manner. Retrovirology $3: 36$.

21. Kobayashi F, Ishida H, Matsui T, Tsuji M (2000) Effects of in vivo administration of anti-IL-10 or anti-IFN-? monoclonal antibody on the host defense mechanism against Plasmodium yoelii yoelii infection. $J$ Veter Med Sci 6: 583-587.

22. Laar AK, Grant FE, Addo Y, Soyori I, Nkansah B, et al. (2013) Predictors of fetal anaemia and cord blood malaria parasitemia among Newborns of HIV-positive mothers. Br Med Central Res Notes 6: 350-356.

23. Lokossou AJ, Dechavanne C, Bouraima A, Courtin D, Le Port A, et al. (2013) Association of IL-4 and IL-10 maternal halotypes with immune responses to P. falciparum in Mothers and Newborns. BioMed Central Infectious.
24. Luty AJF, Lell B, Schmidt-Otto R (1999) Interferon-? responses are associated with resistance to re-infection with Plasmodium falciparum in young African Children. $J$ Infect Dis 179: 980-988.

25. Lyke KE, Burges R, Cissoko Y, Sangare L, Dao M (2004) Serum levels of the proinflammatory cytokines interleukin-1 beta IL-1 beta) IL-6 IL-8 IL-10 Tumor Necrosis Factor alpha and IL-12 p70) in Malian Children with severe Plasmodium falciparum malaria and matched uncomplicated malaria or healthy controls. Infect Immunol 72: $5630-5637$.

26. Mbugi VE, Mejijerink M, Veene Mans J, Jeurink PV, McCall M, et al. (2010) Alterations in early cytokine mediated immune responses to Plasmodium falciparum infection in Tanzanian children with mineral element deficiencies: a cross- sectional survey. Malaria Journal 9: 130 .

27. McIntyre J (2002) Mothers infected with HIV: Reducing maternal death and disability during pregnancy. Br Med Bull 67: 127-135

28. Moore JM, Nahlen BL, Misore A, Lal AA, Udhayakumar V (1999) Immunity to placental malaria elevated Mother-to-child HIV-1 transmission current issues future challenges. AIDS Science.

29. Ned RM, Moore JM, Chaisavaneeyakorn S, Udhayakumar V (2005) Modulation of immune responses during HIV-malaria co-infection in pregnancy. Trends Parasitol 21: 284-291. [Crossref]

30. Niikura M, Kamiya S, Kita K, Kobayashi F (2008) Co-infection with on lethal murine malaria parasites suppresses pathogenesis caused by Plasmodium berghei NK65. $J$ Immunol 180: 6877-6884.

31. Ogbodo SO, Nwagha UI, Okaka ONC, Ogenyi SC, Okoko RO, et al. (2009). Malaria parasitemia among pregnant women in rural community of eastern Nigeria: need for combined measures. Nig J Physiol Sci 24: 95-100.

32. Perrault SD, Hajek J, Zhong K, Owino SO, Sichangi M (2009) Smith Geoffrey Smith Shi P.Y, Moore J.M, Kain C. 2009. Human Immunodeficiency Virus Co-infection increases placental parasite density and transplacental malaria transmission in Western Kenya. Am J Tropical Med Hygiene 80: 119-125.

33. Raghuparty R, Al-Mutawa E, Makhseed M, Azizieh F, Szekeres-Bartho J (2009a) Modulation of cytokine production by dydrogestrone in lymphocytes from women with recurrent miscarriage. BJOG: an Int J Obstetr Gynecol 112: 1096-1101.

34. Singh N, John R (2001) Immune Reconstitution Syndrome and Exacerbation of Infections after Pregnancy. Clin Infec Dis 45:1192-1199.

35. Tian L, Wang T, Lv S, Wang F, Guo J, et al. (2013) HIV and intestinal parasite coinfections among a Chinese population: an immunological profile. Infec Dis of Poverty $2 \cdot 18$

36. Verhoeff HF, Brabin JB, Hart CA, Chimsuku L, Kazelbe P, et al. (1999) Increased prevalence of malaria in HIV-Infected Pregnant women and its implication for malaria control. Trop Med Int Health 4: 5-12.

Copyright: (2017 Adeoti OM. This is an open-access article distributed under the terms of the Creative Commons Attribution License, which permits unrestricted use, distribution, and reproduction in any medium, provided the original author and source are credited. 